\title{
CHARACTERISTICS OF MATRIX STRUCTURES, AND THEIR EFFECTS ON PROJECT SUCCESS
}

\author{
R. Schnetler ${ }^{1}$, H. Steyn ${ }^{2 *} \&$ P.J. van Staden ${ }^{3}$ \\ ${ }^{1,2}$ Department of Engineering and Technology Management \\ Graduate School of Technology Management \\ University of Pretoria, South Africa \\ ${ }^{2}$ herman.steyn@up.ac.za \\ ${ }^{3}$ Department of Statistics \\ University of Pretoria, South Africa.
}

\begin{abstract}
This paper investigates the characteristics of matrix structures and their relationships with drivers of project success, such as communication, collaboration, and trust between project team members. Matrix characteristics that were expected to correlate positively with project success mostly did correlate with the success drivers. However, characteristics expected to impact negatively on project success did not show such significant correlations; some even correlated positively with success drivers. The success drivers investigated, in turn, correlated positively with perceived project success. A proposed model illustrates the effects of matrix characteristics on the drivers of success and their ultimate effect on project performance.
\end{abstract}

\section{OPSOMMING}

Eienskappe van matriks strukture en hul effek op drywers van projeksukses - naamlik kommunikasie, samewerking, en vertroue tussen projek-spanlede - is ondersoek. Eienskappe wat verwag was om positief met projeksukses te korreleer het meestal wel positief gekorreleer met die drywers van sukses. Eienskappe wat verwag was om negatief met projeksukses te korreleer het egter nie sulke beduidende korrelasies getoon nie; sommige het selfs positief gekorreleer met projeksukses. Drywers van sukses het ook positief gekorreleer met waargenome projeksukses. 'n Voorgestelde model illustreer die verwantskappe tussen matriks-eienskappe op kommunikasie, samewerking, en vertroue tussen spanlede, en die uit eindelike effek op projekprestasie.

\footnotetext{
1 The author was enrolled for a Master's degree in Project Management in the Department of Engineering and Technology Management, University of Pretoria.

* Corresponding author
} 
Most firms operating in multi-project environments have to share common resources in order to deliver superior quality outputs fast and cost-effectively. In order to cope with such situations, matrix management was developed in the early 1960s, and was first officially used in the U.S. aerospace industries [1]. Turner [2] defines a matrix structure as an overlap between a functional hierarchy and a project hierarchy. Larson and Gobeli [3] define a matrix structure as "a 'mixed' organizational form in which a normal hierarchy is overlaid by some form of lateral authority, influence, or communication".

Numerous studies have been conducted on the implementation of matrix management and the advantages and problems relating to this type of company structure [4,3]. Although many authors have suggested possible solutions to the problems concerning matrix management in a project environment, empirical data regarding the impact of matrix structures on project management are lacking. Ford and Randolph [4] suggested a number of paradoxes between the advantages and disadvantages of matrix structures. This essentially means that although this organisational structure has many advantages, the disadvantages seem to play off against the advantages, thus leading to 'paradoxes'.

While Gray et al. [5] stated that the matrix organisation is the most frequently-mentioned structure in the literature, indicating its widespread use in modern organisations, much of the literature dealing with matrix structures dates back to the late 1980s and early 1990s. At the end of the $20^{\text {th }}$ century, research interest in project management structures moved towards investigating projects as temporary organisations [6,7]. More recent articles on the matrix structure focused mainly on the implementation of matrix structures [8], the difference in job satisfaction between functional managers and project managers [9], and resource allocation and organisational objectives in matrix organisations [10,11]. Despite the dearth of recent publications, the organisational structure still plays an important role in the overall success of any firm; and, despite all the knowledge available, managers often still seem to experience problems with organisational structures. New ideas and concepts should therefore be of great relevance in helping organisations in this regard.

A preliminary literature survey uncovered three factors that influence overall project success: quality of communication, collaboration between team members, and trust among team members [12]. The first objective of this paper is to identify, from the literature, positive and negative characteristics of matrix structures that might influence project success via these three factors. The second objective is to obtain empirical evidence of the influence of the matrix characteristics on these three factors. The third objective is to confirm that a higher quality of communication and collaboration and trust among project teams (as perceived by the respondents) do indeed correlate with perceived project success. A final objective is to propose a practical model that presents the findings in a useful way for managers involved in matrix structures.

\section{LITERATURE AND PROPOSED MODEL}

The matrix structure, with its various forms [2], is an alternative to the functional structure, the project-based (a.k.a. 'pure project') structure, professional bureaucracy, and adhocracy [13]. Hobday [14] mentions that the matrix structure is strong in areas where the project-based structure is inherently weak. Davis and Lawrence [15] describe a matrix organisation as one with a multiple command system that also includes support mechanisms, cultures, and behaviours that can support the structure. This multiple command system is arguably the cause of much of the confusion associated with matrix structures. In a typical organisation, employees report to a single boss, whereas in a matrix structure, an employee will usually have two bosses (or more than two if the employee works on concurrent projects) [16]. As there are several variations of the common matrix structure, one can argue that each organisation will have a uniquely-tailored structure based on its business needs. 
Matrix organisations create lateral communication channels, which in turn increase the frequency of the communication $[3,4,17]$. However, other studies indicate that matrix structures create ambiguity over roles and resources [3] and that there tends to be conflict between project managers and functional managers $[4,18]$. Such positive and negative characteristics of the matrix structure may affect the quality of communication, collaboration, and trust among team members in various ways, which may in turn have an effect on project success. The rationale for this study is therefore to determine the relationships between matrix structure characteristics (both positive and negative), quality of communication, collaboration, and trust, and ultimately their combined effect on project success.

\subsection{Matrix structure characteristics}

While any organisational structure is prone to inherent risks, the current literature provides evidence of several advantages and disadvantages of the matrix structure. Bannerman $[13,19]$ refers to literature that indicates the following risks: dual reporting leads to the risks of loyalty conflicts and unclear accountabilities; and localised claims to authority (authority bias) and decisions and actions taken in isolation lead to the risk of poor decision-making. Overlaps in responsibility and authority can result in power struggles and conflict, leading to the risk of slow response time. Preoccupation with sectional interests and infighting can result in a tendency toward anarchy, leading to the risk of control problems. Dual reporting, role ambiguity and conflict, and competing objectives and priorities can lead to personnel issues, such as the risk of staff stress and turnover. On the other hand, some advantages noted from the literature include:

- flexibility and quick adaption to changing market and technical requirements $[3,15,20]$;

- $\quad$ effective resource allocation [8];

- $\quad$ increased formal lateral communication [9,21,22]; and

- flexible use of human resources $[3,22]$.

Typical problems associated with matrix structures include:

- $\quad$ tendencies toward anarchy [15];

- $\quad$ power struggles $[3,15,20,23]$;

- $\quad$ collapse during economic crises [15,24];

- $\quad$ excessive overhead costs $[3,9,15]$;

- decision strangulation $[8,15,22]$;

- $\quad$ disruptive conflict $[18,23,25,26]$;

- unclear roles and responsibilities $[8,21,22,23,26]$; and

- because of the relatively large number of managers required, functional managers often double up as project managers (the 'two hat problem') [23].

Galbraith [17] explains that a matrix structure is characterised by having dual authority relationships and a power balance between functional and project managers. He does not, however, state specifically whether these are to the advantage or disadvantage of the organisation. Five common problems with matrix structures were studied by Sy [26]: misaligned goals, unclear roles and responsibilities, ambiguous authority, lack of a matrix guardian, and 'silo-focused' employees were the most cited problems. An interesting observation was the difference in the percentage of top-level and mid-level managers' perceived awareness of these problems [26]. Unclear roles and responsibilities and 'silofocused' employees seem to be more commonly experienced among mid-level managers, whereas the other three are more common among top-level managers. Unclear roles and responsibilities had the largest variance. On the problem of multiple-command conflicts, Engwall and Kälqvist [20] found that these conflicts are mostly due to the competition between projects and not between different departments; but this contradicts other studies that indicate clear conflicts between project managers and functional managers [9]. Hemsley and Vasconcellos [25] studied matrix organisations in Brazil and discovered the 
following three problems with them: selection of the wrong type of matrix, poor implementation, and scant conflict management.

In a study by Turner et al. [9], the different viewpoints and job satisfaction and dissatisfaction criteria between functional managers and project managers are described. From their study, it is evident that functional managers and project managers "failed to agree as to the type of matrix" to be used [9]. This already points to the potential problems of successfully and efficiently managing projects in an organisation where functional and project managers do not agree on the structure, with the consequence of poor outcomes. Greiner and Schein [24] claim that a matrix structure does not operate according to typical hierarchical structures where "authority should equal responsibility", "every subordinate should be assigned to a single boss", and "labor is more efficient if divided into specialized departments". They also described a critical paradox of these structures where an "open and flexible" organisation must be given "closure to prevent anarchy" and "management is everyone's business in a matrix organization" [24]. It is evident that both project managers and functional managers should ideally have a balanced influence over the salary and promotion decisions of the project team members [18]. This, Greiner and Schein [24] states, is to prevent team members from trying to impress the manager whom they believe has the biggest influence over matters.

It is clear from the above observations in the literature that matrix structures, although commonly used, pose many problems, most of which are cited by several authors. One may ask why, if it is known that matrix structures are prone to problems, these problems are not limited or eliminated. A possible answer to this question may be found in the work of Sy [26], who states that companies tend to measure popular key performance indicators (KPIs) such as return on investment, market share, and profitability, with very few companies actually tracking the performance of their matrix structure and its effects on the above three measures. This may be why so few companies are concerned with the effect of the matrix structure on the performance of projects. "Opportunities for successful matrix organisational performance are often found at the intersection of different tasks and projects, intersections where miscommunication, misinterpretation and technical surprises may emerge" [27]. It is this challenge of miscommunication that this paper aims to address by explaining the effects that the quality of the communication has on the organisation.

Wellman [27] states that such challenges can be overcome when teams coordinate with one another in order to integrate their labour instead of coordinating through a formal management structure. This, however, becomes difficult when one deals with multiple concurrent projects. The team members, rather than the responsible project manager(s) or executives, may then decide which project work takes priority. Kuprenas [1] is of the opinion that all the interfaces that are synonymous with matrix structures require good communication skills and team work. He does not, however, describe how these two important but difficult tasks can be handled successfully while dealing with numerous projects at a time.

Ford and Randolph [4] refer to the contradictions between the positive and negative characteristics as 'paradoxes'. Paradoxes from their study include:

- increased frequency of lateral communication vs ambiguity over roles, responsibility, and conflict between functional managers and project managers;

- $\quad$ improved motivation and commitment vs heightened conflict among employees; and

- $\quad$ high ability to process information vs decision strangulation and slow response times.

Some of the most frequently-cited positive and negative characteristics of matrix structures that are investigated further in this study are summarised in Table 1. 
Table 1: Matrix structure characteristics

\begin{tabular}{|l|l|}
\hline Positive characteristics & References \\
\hline Flexibility in use of human resources & $3 ; 4 ; 8 ; 9 ; 22$ \\
\hline Individual motivation & $3 ; 4 ; 9$ \\
\hline Job satisfaction & $4 ; 9 ; 23$ \\
\hline Increased frequency of communication & $3 ; 9 ; 21 ; 22$ \\
\hline Negative characteristics & $3 ; 4 ; 9 ; 15$ \\
\hline Higher overhead costs & $4 ; 9 ; 8 ; 13 ; 15 ; 19 ; 22$ \\
\hline $\begin{array}{l}\text { Delayed decision-making / decision strangulation / poor } \\
\text { decisions }\end{array}$ & $3 ; 4 ; 9 ; 18 ; 19 ; 20 ; 23 ; 25 ; 26$ \\
\hline Creates disruptive conflict & $3 ; 9 ; 13 ; 19 ; 23$ \\
\hline Unclear reporting structures & $15 ; 13 ; 19 ; 24$ \\
\hline Becomes anarchic & $13 ; 15 ; 18 ; 19 ; 20 ; 23 ; 24$ \\
\hline Power struggles / authority issues & $4 ; 8 ; 15 ; 21 ; 22 ; 26$ \\
\hline Unclear roles & $3 ; 4 ; 8 ; 13 ; 15 ; 19 ; 21 ; 22 ; 23 ;$ \\
\hline Unclear responsibilities / accountabilities & 26 \\
\hline
\end{tabular}

\subsection{Communication, collaboration, and trust}

In a case study on matrix organisations and management concepts, Wellman [27] found that communication was mentioned by interviewees twice as often as any of the other concepts. After a number of interview iteration rounds to get to a relationship model, he developed a model that places communication at the centre of all the management concepts in a matrix organisation. Wellman [27] remarked that "in the end it seemed that Communication was an integrating concept that bridged many of the other concepts" [27].

"Collaboration can be described as a social group dependant on trust as a form of capital investment for the attainment of goals and objectives" [28]. This statement clearly indicates the effects and influence of trust and collaboration on one another. Herzog [29] states that trust is the foundation for building successful collaborations [28], and there are similar statements in other literature. A finding from a study by Leufkens and Noorderhaven [30] indicates that relationships are extremely important in ensuring proper collaboration on a project. Sy [26] found similarly that in companies with a collaborative culture, the infamous problem of ambiguous authority is usually resolved as team members collaborate in order to find a solution or to complete a task, regardless of who has authority. Informal negotiations are typically used in order to achieve this. This may indicate that ambiguous authority (a renowned matrix structure disadvantage, as discussed earlier) may be countered by proper collaboration between project team members. This may show a potential paradox, as collaboration and trust are affected by role ambiguity and power struggles.

Other literature indicates the following:

- $\quad$ increased collaboration and trust impact positively on project success [31];

- increased frequency of communication in matrix structures decreases quality of communication in certain instances [21];

- $\quad$ improved communication impacts positively on project success [32];

- collaboration decreases role and authority ambiguities [26];

- $\quad$ more frequent communication improves collaboration and trust in a programme [12]; and

- $\quad$ forcing (conflict management) reduces trust [21]. 
Bartlett and Ghoshal [33] explain how firms usually adopt a matrix structure and correctly identify the goal as well as the need for a multi-dimensional structure. The firm should, however, also be defined in terms of its physiology and psychology, not only its basic structure [33]. Altering and instilling the organisational psychology should therefore be the first objective [33]. This clearly explains how the development of a successful matrix organisation stretches far beyond merely structural terms. The organisation comprises people with emotions, feelings, and relationships. Understanding how these affect the organisation, and their effect on project success, is an undeniable aspect of the development of an organisation. Communication, collaboration, and trust are but a few of the influential factors brought about by people within an organisation and its project teams; "Managing people effectively influences many results of a project" [34].

\subsection{The model investigated, and hypotheses}

There are good reasons to believe that the quality of communication, collaboration between team members, and trust between team members contribute to overall project success [12]. What is not clear from the literature, however, is the effect that the positive and negative characteristics listed in Table 1 might have on these three factors - viz. communication, collaboration, and trust. This paper contributes to understanding the effect that the matrix characteristics listed in Table 1 have on these three factors and, through them, on project success.

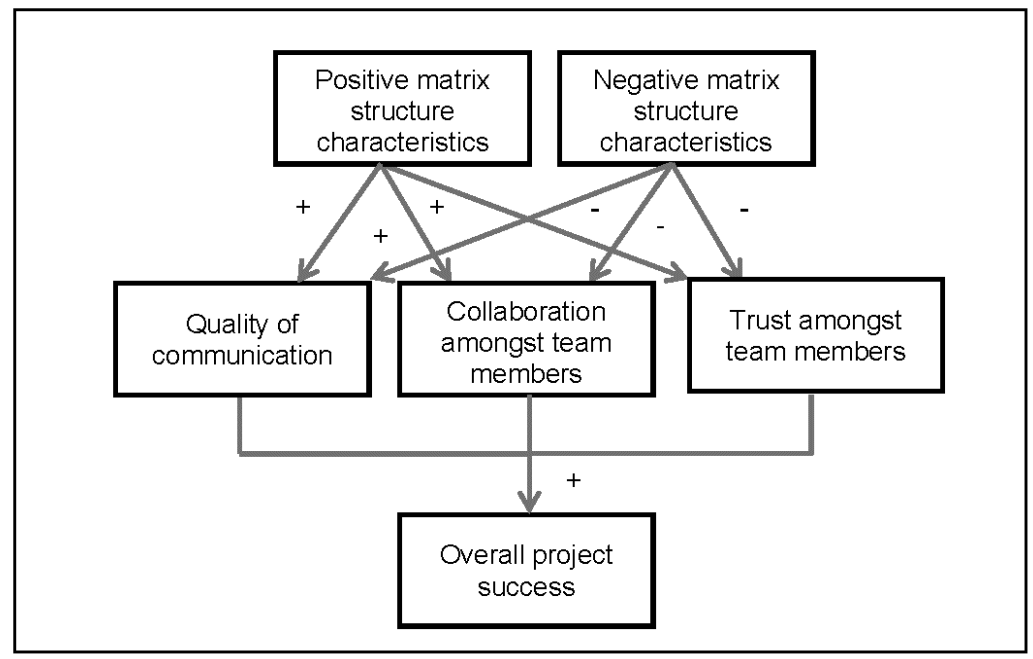

Figure 1: Matrix structure characteristics and project success model

From the above literature, a model was developed that is represented in Figure 1 . The following hypotheses were used to test and eventually expand this model:

\section{Hypothesis I:}

$H_{0}$ : There is no correlation between the 'positive matrix structure characteristics' listed in Table 1 and the quality of communication and the collaboration and trust among project teams.

$H_{a}$ : There is a positive correlation between the 'positive matrix structure characteristics' listed in Table 1 and the quality of communication and the collaboration and trust among project teams. 
Hypothesis II:

$H_{0}$ : There is no correlation between the 'negative matrix structure characteristics' listed in Table 1 and the quality of communication and the collaboration and trust among project teams.

$H_{a}$ : There is a negative correlation between the 'negative matrix structure characteristics' listed in Table 1 and the quality of communication and the collaboration and trust among project teams.

Hypothesis III:

$H_{0}$ : Higher quality communication and higher levels of collaboration and trust among project teams do not correlate with perceived project success.

$H_{a}$ : Higher quality communication and higher levels of collaboration and trust among project teams positively correlate with perceived project success.

\section{RESEARCH METHOD}

The characteristics of matrix structures (Table 1) and their possible paradoxical nature within the organisation were investigated. The sampling method therefore included a reasonable number of different project team members from as many South African industries as possible. For convenience, and because of time constraints, a non-probability sample (convenience/accidental sample) was drawn. The sample is therefore not representative of the entire population, and the results are not meant to be generalised to the entire population, merely to the subjects studied. The sample of approximately 2,800 people included those who attended a project management certificate course at the University of Pretoria, current and past students of the Masters' Programmes in Engineering Management and Project Management from the same university, and people employed at South African organisations in the engineering, mining, services, and government sectors who are involved in managing projects. The study made use of a single questionnaire, which was constructed with Adobe Acrobat X Pro and was distributed by means of electronic mail. Responses from the returned questionnaires were extracted with Adobe Acrobat X Pro in Excel format. All data analysis was performed using SAS V9.3 under Windows XP SP3.

\section{RESULTS}

A total of 121 completed questionnaires were received. Fifteen respondents indicated that they had no experience in a matrix environment, and so their questionnaires were discarded. Thus 106 questionnaires were used in the study.

\subsection{Descriptive analysis}

Respondents came from the following industries: engineering and construction (48 respondents), minerals and mining (15 respondents), and government ( 23 respondents). Combined, these made up 81 per cent of all questionnaires received. The other industries were all represented by eight or fewer respondents, making up the remaining 19 per cent. Respondents with ten or less years' experience in a matrix environment accounted for 83 per cent of responses received. It can therefore be assumed that the majority of the respondents are relatively young and have less than ten years' experience in their respective fields. The distribution of roles was as follows: 37 project managers, 30 functional managers, 36 other team members, and only 3 CEOs or executives. A relatively good spread of project roles (project manager, functional manager, and project team member) was therefore available.

The number of concurrent projects in which respondents were involved ranged between one and 200. The higher numbers of concurrent projects (25 and more) were mainly from functional managers and executives; 75 per cent of respondents were working on between one and six concurrent projects.

Respondents' views regarding the effects that various matrix structure characteristics have on project success within the respondents' firms were obtained. Response frequencies were fairly evenly distributed between 'no noticeable effect', 'considerable effect' and 'immense effect'. 'Almost no effect' had very low response frequencies for all 12 
characteristics indicated in Table 1. The average highest response frequency for all characteristics was, however, within the 'considerable effect' range; one can therefore already comment that the general feeling among respondents was that all the characteristics (both positive and negative) play a significant role in project success.

Similar results were found when respondents were asked to rate various aspects based on the effect they have on project success. Most of the aspects had high frequency ratings $(>50 \%)$ for 'above average' and more than 25 per cent for 'good'. Since the study focused on communication, collaboration, and trust, it is worth noting that for quality of communication and for collaboration among team members, 77 per cent and 81 per cent of respondents, respectively, rated these two factors as 'above average' to 'good'. Trust between team members, however, showed only 69 per cent of respondents rating it 'above average' to 'good', with 29 per cent of respondents rating trust between team members 'below average'. Overall team performance and overall project success also scored very high, with 85 per cent and 87 per cent of respondents rating these factors as 'above average' to 'good' respectively.

\subsection{Bivariate and multivariate statistical analysis}

\subsubsection{Positive and negative characteristics of matrix structures}

Although for statistical reasons it was not stated as such in the questionnaire, the matrix structure characteristics were grouped as 'positive' (advantageous) and 'negative' (disadvantageous). These characteristics were grouped as indicated in Table 1.

Cronbach alpha $(a)$ tests for both the positive and the negative groups of characteristics were performed in order to determine the coherence of the variables within each group. In the case of the positive characteristics, the $a$-value returned was 0.69 , while for the negative characteristics it was 0.88 . The lower $a$-value for the positive characteristics test may result from the fact that only four positive variables were included, compared with the eight negative variables. Both $a$-values were considered acceptable, and one can confidently say that there is definite coherence between the variables in each of the two groups. Table 2 contains the Pearson correlation coefficients of the 'positive' characteristics with $p$-values all less than 0.005 , while Table 3 shows the Pearson correlation coefficients for the 'negative' characteristics, with all $p$-values also less than 0.005 .

The mean difference between the responses of the two groups of paired variables (positive characteristics minus negative characteristics) is 0.22 . A paired $t$-test was therefore performed to test whether the mean response of the positive characteristics is significantly higher than the mean response of the negative characteristics. A $t$-value of 2.74 with a corresponding $p$-value of 0.004 was calculated, leading to the conclusion that respondents rate the effect that the positive characteristics have on project success considerably higher than they rate the negative characteristics.

Table 2: Positive characteristics - Pearson correlation coefficients

\begin{tabular}{|l|cccr|}
\hline & 1 & 2 & 3 & 4 \\
\hline 1. Increased frequency of communication & 1 & & & \\
2. Flexibility in the use of human resources & 0.378 & 1 & & \\
3. Job satisfaction & 0.349 & 0.327 & 1 & \\
4. Individual motivation & 0.364 & 0.309 & 0.394 & 1 \\
\hline
\end{tabular}

All $p$-values $<0.005, N=106$, Cronbach $a=0.69$

\subsubsection{Matrix structure characteristics and the effect on communication, collaboration, and trust}

All of the matrix structure characteristics listed in Table 1 were tested individually for statistical significance against the three factors influencing project success: quality of 
Table 3: Negative characteristics - Pearson correlation coefficients

\begin{tabular}{|lllllllll|}
\hline & 1 & 2 & 3 & 4 & 5 & 6 & 7 & 8 \\
\hline 1. Unclear responsibilities & 1 & & & & & & & \\
2. Higher overhead costs & 0.444 & 1 & & & & & & \\
3. Power struggles & 0.281 & 0.319 & 1 & & & & & \\
4. Delayed decision-making & 0.364 & 0.350 & 0.551 & 1 & & & & \\
5. Unclear reporting & & & & & & & \\
structure & 0.500 & 0.294 & 0.503 & 0.436 & 1 & & & \\
6. Creates conflict & 0.365 & 0.416 & 0.556 & 0.514 & 0.566 & 1 & & \\
7. Unclear roles & 0.526 & 0.342 & 0.504 & 0.562 & 0.689 & 0.575 & 1 & \\
8. Becomes anarchic & 0.484 & 0.376 & 0.546 & 0.634 & 0.655 & 0.608 & 0.684 & 1 \\
\hline All $p$-values < $0.005, N=106$, & Cronbach & $a=0.88$ & & & & & & \\
\hline
\end{tabular}

communication, collaboration among team members, and trust between team members, as well as overall team performance and overall project success. After initial testing, the results were improved by grouping the Likert scale options into two groups. On the question relating to the characteristics, 'no effect' and 'little effect' were grouped together, while 'considerable effect' and 'immense effect' were grouped together. For the question on project success factor ratings, the two new groups were 'poor/below average' and 'above average/good'. A Chi-square test was conducted on each of the variable pairs and the following became evident:

- $\quad$ increased frequency of communication was shown to be significant at a 5 per cent level with all of the quality of communication, collaboration, and trust. It should be noted that there is a positive correlation between an increase in communication and the quality of communication, as opposed to previous studies where an increase in communication corresponded with a decrease in the quality of communication (see, for instance, Joyce [21]);

- unclear responsibilities and higher overhead costs showed no significance (at a 5 per cent level) to any of the factors leading to project success;

- delayed decision-making proved to be significant at a 1 per cent level with quality of communication ( $p$-value $=0.008$ ) and at a 5 per cent level with collaboration among team members $(p$-value $=0.023)$, but was not significant with trust between team members;

- $\quad$ the fact that matrix structures become anarchic was significant at a 1 per cent level with quality of communication ( $p$-value $=0.0003$ ), but only at a 10 per cent level with collaboration among team members $(p$-value $=0.058)$ and trust between team members $(p$-value $=0.079)$;

- $\quad$ at a 5 per cent significance level, six of the 12 characteristics showed a relationship to both overall team performance and overall project success: increased communication, delayed decision-making, unclear reporting structures, conflict creation, unclear roles, and the chaotic nature of matrix structures.

Considering the three success drivers, the following points emerged:

- $\quad$ quality of communication showed significance at a 1 per cent level to an increase in communication $(p$-value $=0.004)$, delayed decision-making $(p$-value $=0.008)$, and the chaotic nature (anarchic) of matrix structures ( $p$-value $=0.0003$ );

- collaboration among team members related statistically to increased communication $(p$-value $=0.003)$ and job satisfaction $(p$-value $=0.002)$ at a 1 per cent significance level, and to delayed decision-making $(p$-value $=0.023)$ at a 5 per cent significance level; and 
- $\quad$ trust between team members showed significant relations at a 5 per cent level with the positive characteristics of increased communication $(p$-value $=0.032)$, flexibility in the use of human resources $(p$-value $=0.032)$, and job satisfaction $(p$-value $=0.019)$.

The above list of significant pairs of variables does not demonstrate, however, any correlation between the factors. Further tests were conducted on the significant variable pairs in order to determine whether there was any correlation. In order to test Hypotheses I and II, the positive and negative matrix characteristics were tested for correlation with the quality of communication, collaboration among team members, and trust between team members, and with overall team performance and overall project success by means of Spearman correlation tests.

From Table 4 it becomes clear that Hypotheses I and II may be more complicated than derived here, since not all characteristics showed significant correlations. Although many of the positive characteristics had a positive correlation with communication, collaboration, and trust, not all of the characteristics showed statistically significant results at a 5 per cent level of significance. Technically, the hypotheses should be expanded further to include a hypothesis for each characteristic against each variable tested. This would, however, have resulted in too many hypotheses for this study. It could be proved that:

a) at a 5 per cent significance level, there is a positive correlation between increased frequency of communication and quality of communication, as well as between increased frequency of communication and trust between team members;

b) at a 5 per cent level of significance, there is a positive correlation between flexibility in the use of human resources and collaboration, as well as between flexibility in the use of human resources and trust among team members;

c) at a 1 per cent significance level, there is a positive correlation between job satisfaction and collaboration, while at a 5 per cent level of significance, there is a positive correlation between job satisfaction and trust among team members; and

d) at a 5 per cent level of significance, there is a positive correlation between individual motivation and collaboration, as well as between individual motivation and trust among team members.

Based on the above, the null hypothesis of Hypothesis I can therefore only be rejected for some pairwise comparisons.

Table 4: Spearman coefficients for positive characteristics vs success drivers

\begin{tabular}{|l|llll|}
\hline & $\begin{array}{l}\text { Increased frequency } \\
\text { of communication }\end{array}$ & $\begin{array}{l}\text { Flexibility in the } \\
\text { use of human } \\
\text { resources }\end{array}$ & $\begin{array}{l}\text { Job } \\
\text { satisfaction }\end{array}$ & $\begin{array}{l}\text { Individual } \\
\text { motivation }\end{array}$ \\
\hline Quality of communication & $0.223^{* *}$ & 0.103 & 0.160 & $0.163^{*}$ \\
Collaboration among team & $0.164^{*}$ & $0.194^{* *}$ & $0.264^{* * *}$ & $0.196^{* *}$ \\
Trust between members & $0.205^{* *}$ & $0.215^{* *}$ & $0.216^{* *}$ & $0.203^{* *}$ \\
Overall team performance & $0.265^{* * *}$ & $0.280^{* * *}$ & $0.242^{* *}$ & $0.194^{* *}$ \\
Overall project success & $0.247^{* *}$ & $0.218^{* *}$ & $0.194^{* *}$ & $0.220^{* *}$ \\
\hline$N=106,{ }^{*} p$-value $<0.1,{ }^{* *} p$-value $<0.05,{ }^{* * *} p$-value $<0.01$ & & \\
\hline
\end{tabular}

Importantly, the study found statistically significant positive correlations between all of the positive characteristics and overall team performance, and also between all of the positive characteristics and overall project success. The positive characteristics from matrix structures therefore seem to impact positively on team performance and project success for the population in this study.

In Table 5, the negative characteristics do not reflect the negative correlations with the success drivers as originally anticipated. There are only two statistically significant 
Table 5: Spearman coefficients for negative characteristics vs. success factors

\begin{tabular}{|l|l|l|l|l|l|l|l|l|}
\hline & $\begin{array}{l}\text { Unclea } \\
\text { r resp. }\end{array}$ & $\begin{array}{c}\text { Higher } \\
\text { o/h costs }\end{array}$ & $\begin{array}{c}\text { Power } \\
\text { struggles }\end{array}$ & $\begin{array}{c}\text { Delayed } \\
\text { decision- } \\
\text { making }\end{array}$ & $\begin{array}{c}\text { Unclear } \\
\text { reporting } \\
\text { structure } \\
\text { s }\end{array}$ & $\begin{array}{c}\text { Creates } \\
\text { conflict }\end{array}$ & $\begin{array}{c}\text { Unclear } \\
\text { roles }\end{array}$ & $\begin{array}{c}\text { Becomes } \\
\text { anarchic }\end{array}$ \\
\hline $\begin{array}{l}\text { Quality of } \\
\text { communicatio } \\
\mathrm{n}\end{array}$ & -0.016 & $0.164^{*}$ & -0.130 & -0.158 & -0.112 & $-0.214^{* *}$ & -0.093 & $-0.295^{* * *}$ \\
\hline Collaboration & $0.178^{*}$ & $0.198^{* *}$ & 0.039 & -0.020 & 0.017 & -0.026 & -0.044 & -0.095 \\
\hline Trust & $0.175^{*}$ & 0.017 & -0.029 & -0.016 & 0.079 & -0.014 & 0.020 & -0.040 \\
\hline $\begin{array}{l}\text { Overall team } \\
\text { performance }\end{array}$ & -0.048 & -0.103 & -0.110 & $-0.236^{* *}$ & $-0.178^{*}$ & $-0.210^{* *}$ & $-0.244^{* *}$ & $-0.241^{* *}$ \\
\hline $\begin{array}{l}\text { Overall } \\
\text { project } \\
\text { success }\end{array}$ & -0.014 & 0.035 & -0.148 & -0.118 & $-0.252^{* * *}$ & $-0.179^{*}$ & -0.156 & -0.158 \\
\hline
\end{tabular}

correlations (both negative) at a 1 per cent significance level, while there are six more statistically significant correlations at a 5 per cent level of significance, of which five are negative. There is no statistically significant correlation between any of the three success drivers (quality of communication, collaboration, and trust) and power struggles, delayed decision-making, unclear reporting, or unclear roles. Unclear responsibilities had an unexpectedly weak positive correlation with collaboration and with trust between team members. This means that, where high levels of unclear responsibilities are present, higher levels of collaboration and trust among the members in the project team were also recorded. One could argue that teams operate in a more coherent way when there are no clear responsibilities, since this may actually bond the group as they attempt to complete the tasks. Higher overhead costs were present where there were higher levels of quality of communication and collaboration.

The only two characteristics that possess statistically significant negative correlations with quality of communication are conflict creation and the anarchic nature of matrix structures.

As in the case of Hypothesis I, the null hypothesis of Hypothesis II can therefore only be rejected for some pairwise comparisons.

Delayed decision-making, unclear reporting structures, unclear roles, conflict creation, and chaos all negatively correlate to overall team performance. Although very few of the negative characteristics seem statistically to influence communication, collaboration, and trust, a number of them do correlate with a decrease in team performance. Unclear reporting structures and conflict creation correlate negatively with overall project success, albeit only at a 10 per cent significance level in the case of conflict creation.

\subsubsection{Communication, collaboration, and trust and the effect on overall project success}

In order to confirm the final part of the proposed model, Hypothesis III was considered.

Significance tests were done for the success variables of quality of communication, collaboration among team members, and trust between team members measured against overall project success. In all three cases, Fisher's exact test gave $p$-value $<0.01$. A Spearman correlation test was done subsequently to establish whether there are any correlations between the three success drivers and overall project success. Each of the three variables showed a strongly positive correlation to overall project success. Table 6 contains the Spearman correlation coefficient for each of the three variables as tested against project success. 
Table 6: Spearman correlation coefficients for the three success drivers

Quality of communication

0.496

Collaboration among team members

Trust between team members

0.351

$N=106, p$-value $<0.001$

From the above, the null hypothesis of Hypothesis III is rejected for all three variables, and thus all three variables exhibit a statistically-significant positive correlation with project success.

This finding is in line with previous studies conducted by Yang et al. [35] and Maurer [29]. Although their respective studies did not measure the factors in a matrix environment as such, this study proves that, for the population concerned, there are similar results to previous studies within matrix structures as well.

\section{CONCLUSION AND RECOMMENDATIONS}

\subsection{Adapted model based on research results}

Based on the results from the hypotheses tested, the model illustrated in Figure 1 had to be expanded to portray the findings and to include 'overall team performance' as a success driver. Overall team performance was added to the model, since the responses to this variable showed very significant correlations with both the positive and the negative characteristics. The new model is shown in Figure 2. Characteristics that showed no significant correlations were excluded from the model. This model shows a clear summary of the positive and negative correlations between the matrix characteristics and the success drivers. What is evident from this model (confirmed by the empirical results) is the fact that many of the negative characteristics actually have positive correlations with the success drivers. Furthermore, although all the positive characteristics feature in the model, not all of the negative characteristics showed significant correlations with the success drivers. All four of the success drivers proved to be significantly correlated to overall project success, which now features as the centre-point of the model.

The inner part of the model in Figure 2 proved to be statistically significant with strong positive correlations of (a) the quality of communication, (b) collaboration, and (c) trust with overall team performance and with overall project success. This is in agreement with previous studies $[29,35]$. These studies do not mention, however, the specific organisational structures in which the results were measured. On the other hand, this study proved that the correlations are present within matrix structured organisations, at least for the sample pertaining to this study.

\subsection{Associations of results with previous studies}

Yang et al. [35] show that team work, collaboration, communication, and team cohesiveness have a positive effect on project success, while Maurer [29] also measured an increase in project success with increased levels of collaboration and trust. While these studies do not refer to matrix structures as such, this study found these correlations also to be present in project teams working in matrix organisations. While Joyce [21] argues that an increase in communication frequency may cause a decrease in the quality of the communication, this study showed the opposite: higher frequencies of communication positively correlated with better quality communication. When considering the negative characteristic of unclear roles, Katz and Allen [18] proved that higher levels of role clarity correlated positively to project performance. Since unclear roles proved to have a significant negative correlation with project team performance and hence with overall project success, their results were confirmed for matrix structures in this study. Sy [26] found that ambiguities relating to role and authority led to a decrease in collaboration, but 
these results could not be proved in this study since both unclear roles and unclear reporting structures showed no significant correlation to collaboration.

Similar perceptions of project managers and functional managers of project success driver performance, team performance, and project success contradict the findings in previous studies [9,10]; these previous studies indicate how project managers and functional managers 'disagree' on many levels when it comes to matrix structures. This study seems to suggest that, although there are distinct differences in the way that project managers and

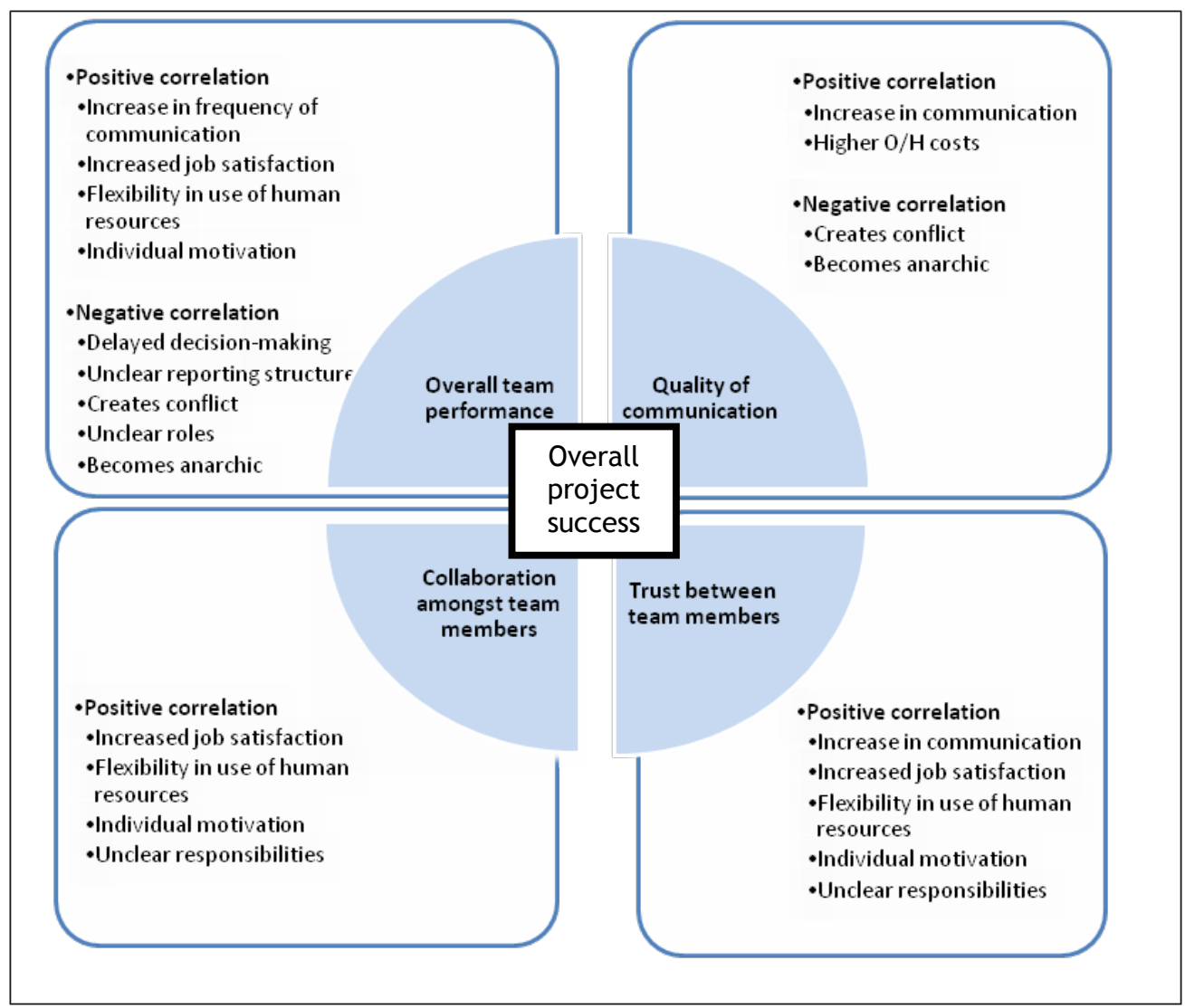

Figure 2: Expanded model of the influences of matrix characteristics on project success

functional managers may want to operate within a matrix structure, their perceptions of the eventual outcome of projects are fairly similar.

\subsection{Practical application of the model}

It is clear that enriched communication improves trust; from the literature [12] it is also clear that communication can lead to better collaboration. Collaboration and trust in turn contribute to project success. The matrix structure lends itself to an increase in the frequency of communication, and managers in matrix organisations should facilitate and promote both the frequency and the quality of communication. Some ideas to promote communication include, for example, the intentional creation of opportunities for informal communication, and co-locating project team members as far as possible.

The fact that not all of the 'negative' characteristics proved to have a negative effect on the quality of communication, collaboration, and trust should be of interest to both project managers and functional managers. This may imply that, although 'negative' characteristics exist, many of them may actually have a positive influence on communication, 
collaboration, and trust. This can be brought into effect by the team members as they struggle through the problems posed by the negative characteristics or disadvantages. In the course of the struggles, the teams may actually improve their levels of collaboration and trust while ensuring good quality communication, so as to limit any negative impacts on the execution of the projects. Team members can, for example, be encouraged to discuss responsibilities and to use techniques such as responsibility assignment matrixes to clarify responsibilities. The attention of team members can also be drawn to the fact that conflict can be constructive.

In summary, project managers, functional managers, and other team members should not necessarily oppose the 'negative' characteristics, but should rather use them to good effect. Most of the 'positive' characteristics in this study did, however, show a positive relationship with the success drivers. Teams should aim to identify these characteristics and to exploit them as far as possible. Both the 'positive' and 'negative' characteristics can only be recognised if teams are aware of their existence; they therefore need to understand the basics of matrix structures. Project teams should ideally identify their specific positive and negative characteristics for each of the four factors in the inner circle of the proposed model. A positive characteristic of one of the four factors may perhaps be a negative characteristic for another team. The study proved that not all 'negative' characteristics that are identified typically with matrix structures necessarily have a negative correlation with project success drivers. The opposite argument also holds. Teams should therefore be aware of the correlations and influences of matrix structure characteristics on project success drivers in their specific and unique environment. In this way, a project team can proactively exploit both positive and negative characteristics to ensure increased project performance.

The fact that team performance in a matrix environment is not typically a key performance area measured by the executive committee of a company [26] should be of concern to any matrix structured company struggling with team performance and project success. Companies with matrix structures should therefore consider developing measures related to team performance for inclusion in merit assessments. As suggested by Sy [26], companies should continually track team performance and its effect on success drivers such as communication, collaboration, and trust, as well as its eventual effect on project outcomes. Only once this is done will people within the whole firm, including all roles and levels, become aware of the dynamics of the organisational structure in which they operate, in order to identify its advantages and limitations. The list of 'positive' and 'negative' characteristics used in this study is by no means exhaustive. Companies and project teams should therefore identify the specific matrix characteristics pertaining to their environment, in order to exploit them to achieve successful project outcomes, while establishing a collaborative and trust culture among all employees. Companies or project teams can also extend their own models by identifying and including their unique success drivers. Identified matrix characteristics along with company-specific success drivers can then assist in achieving increased project performance.

\subsection{Limitations of the results}

Although probability sampling would have yielded a significantly better external validity, it was simply not economically viable to extract a representative sample from the entire population of matrix organisations within South Africa. A non-probability sample in the form of a convenience or accidental sample was therefore taken, which has its own limitations, these being mostly the external validity of the results. It is very difficult, if not impossible, to generalise the findings of this study to the entire population of matrix organisations because a representative sample was not used. However, it can be argued that a reasonably wide variety of industries were represented in this study, and that many of its findings might also pertain to other matrix organisations not included in it. Project managers, functional managers, and project team members were also reasonably well-represented, and this further strengthens the validity of the results obtained. 


\subsection{Suggestions for future research}

From the findings discussed in this study, it is evident that a number of future research topics may flow from the results.

First, the final model proposed in this paper (Figure 2) could be confirmed by structured equation modelling. The challenge with structured equation modelling, however, is that a large number of respondents are required; alternatively, a probabilistic sample of sufficient size must be achieved.

The list of matrix structure characteristics used in this study can be expanded to include many more characteristics, especially positive ones, as these may have been underrepresented in this study. The characteristics' influences on other success factors should also be studied in order to understand the broader influence of the characteristics on both company and project performance. Further studies should be conducted to understand how matrix structure performance can be measured and reported in order to establish a theoretical model that can be used by firms to track and improve the performance of their matrix structure in order to improve levels of project success.

\section{ACKNOWLEDGEMENT}

The authors express their gratitude to $\mathrm{Dr}$ Mike van der Linde for his contribution to this work.

\section{REFERENCES}

[1] Kuprenas, J.A. 2003. Implementation of a matrix organization structure. International Journal of Project Management, 21, pp. 51-62.

[2] Turner, J.R. \& Muiller, R. 2003. On the nature of the project as a temporary organization. International Journal of Project Management, 21, pp. 1-8.

[3] Larson, E.W. \& Gobeli, D.H. 1987. Matrix management: Contradictions and insights. California Management Review, 29, pp. 126-138.

[4] Ford, R.C. \& Randolph, W.A. 1992. Cross-functional structures: A review and integration of matrix organization and project management. Journal of Management, 18(2), pp. 267-294.

[5] Gray, C., Dworatschek, S., Gobeli, D., Knoepfel, H. \& Larson, E. 1990. International comparison of project organization structures: Use and effectiveness. International Journal of Project Management, 8(1), pp. 26-32.

[6] Lundin, R.A. \& Söderholm, A. 1995. A theory of the temporary organization. Scandinavian Journal of Management, 11(4), pp. 437-455.

[7] Turner, J.R. \& Muiller, R. 2003. On the nature of the project as a temporary organization. International Journal of Project Management, 21, pp. 1-8.

[8] Mattila, M., Hallikainen, P. \& Rossi, M. 2010. Challenges in implementing enterprise system functionalities in a matrix organization. Proceedings of the International Conference on Research Challenges in Information Science (RCIS), Nice, France, 21st May 2010. Retrieved from http: //ieeexplore.ieee.org/xpl/freeabs_all.jsp?arnumber=5507299. Accessed in September 2012.

[9] Turner, S.G., Utley, D.R. \& Westbrook, J.D. 1998. Project managers and functional managers: A case study of job satisfaction in a matrix organization. Project Management Journal, 29(3), pp. 11-19.

[10] Laslo, Z. \& Goldberg, A.I. 2001. Matrix structures and performance: The search for optimal adjustment to organisational objectives. IEEE Transactions on Engineering Management, 48(2), pp. 144-156.

[11] Laslo, Z. \& Goldberg, A.I. 2008. Resource allocation under uncertainty in a multi-project matrix environment: Is organisational conflict inevitable? International Journal of Project Management, 26, pp. 733-788.

[12] Bond-Barnard, T.J., Steyn, H. \& Fabris-Rotelli, I. 2013. The impact of a call centre on communication in a programme and its projects. International Journal of Project Management; 31 (7), pp. 1006-1016.

[13] Bannerman, P.L. 2010. Structuring risk into projects. PMI Research and Education Conference, Washington DC.

[14] Hobday, M. 2000. The project-based organisation: An ideal form for managing complex products and systems? Research Policy, 29, pp. 871-893. 
[15] Davis, S.M. \& Lawrence, P.R. 1978. Problems of matrix organisations. Harvard Business Review, May/June, pp. 131-142.

[16] Sayles, L.R. 1976. Matrix management: The structure with a future. Organizational Dynamics, Autumn, pp. 2-17.

[17] Galbraith, J.R. 1971. Matrix organisation designs: How to combine functional and project forms. Business Horizons, 17(1), pp. 29-40.

[18] Katz, R. \& Allen, T.J. 1985. Project performance and the locus of influence in the R\&D matrix. Academy of Management Journal, 28(1), pp. 66-87.

[19] Bannerman, P.L. 2009. Risk implications of software project organization structures. Australian Software Engineering Conference, IEEE.

[20] Engwall, M. \& Källqvist, A.S. 2001. Dynamics of a multi-project matrix: Conflicts and coordination. Stockholm, Sweden. Retrieved from http://www.fenix.chalmers.se/ index.php/publications/2001. Accessed on 31 March 2012.

[21] Joyce, W.F. 1986. Matrix organization: A social experiment. Academy of Management Journal, 29(3), pp. 536-561.

[22] Sy, T. \& Côté, S. 2004. Emotional intelligence: A key ability to succeed in the matrix organization. Journal of Management Development, 23(5), pp. 437-455.

[23] Nicholas, J.M. \& Steyn, H. 2012. Project management for engineering, business and technology, $4^{\text {th }}$ edition. New York: Routledge.

[24] Greiner, L.E. \& Schein, V.E. 1981. The paradox of managing a project-orientated matrix: Establishing coherence within chaos. Sloan Management Review, 22(2), pp. 17-22.

[25] Hemsley, J.R. \& Vasconcellos, E. 1983. Future directions for matrix organizations in Brazil. Project Management Journal, 1(2), pp. 107-114.

[26] Sy, T. 2005. Challenges and strategies of matrix organizations: Top-level and mid-level managers' perspectives. Human Resource Planning Journal, (28)1, pp. 39-48.

[27] Wellman, J. 2007. Leadership behaviours in matrix environments. Project Management Journal, 38(2), pp. 62-74.

[28] Herzog, V.L. 2001. Trust building on corporate collaborative project teams. Project Management Journal, 32(1), pp. 28-37.

[29] Maurer, I. 2010. How to build trust in inter-organizational projects: The impact of project staffing and project rewards on the formation of trust, knowledge acquisition and product innovation. International Journal of Project Management, 28, pp. 629-637.

[30] Leufkens, A.S. \& Noorderhaven, N.G. 2011. Learning to collaborate in multi-organizational projects. International Journal of Project Management, 29, pp. 432-441.

[31] Turner, J.R. \& Muiller, R. 2004. Communication and co-operation on projects between the project owner as principal and the project manager as agent. European Management Journal, 22(3), pp. 327-336.

[32] Thomas, S.R., Tucker, R.L. \& William, R.K. 1999. Compass: An assessment tool for improving project team communications. Project Management Journal, 30(4), pp. 15-24.

[33] Bartlett, C.A. \& Ghoshal, S. 1990. Matrix management: Not a structure, a frame of mind. Harvard Business Review, 68(4), pp. 138-145.

[34] Belout, A. 1998. Effects of human resource management on project effectiveness and success: Toward a new conceptual framework. International Journal of Project Management, 16(1), pp. 21-26.

[35] Yang, L., Huang, C. \& Wu, K. 2011. The association among project managers' leadership style, teamwork and project success. International Journal of Project Management, 29, pp. 258-267. 